This item was submitted to Loughborough's Research Repository by the author.

Items in Figshare are protected by copyright, with all rights reserved, unless otherwise indicated.

\title{
Mapping synergies and trade-offs between energy and the sustainable development goals: A case study of off-grid solar energy in Rwanda
}

PLEASE CITE THE PUBLISHED VERSION

https://doi.org/10.1016/j.enpol.2020.112028

PUBLISHER

Elsevier

VERSION

AM (Accepted Manuscript)

\section{PUBLISHER STATEMENT}

This paper was accepted for publication in the journal Energy Policy and the definitive published version is available at https://doi.org/10.1016/j.enpol.2020.112028.

\section{LICENCE}

CC BY-NC-ND 4.0

\section{REPOSITORY RECORD}

Bisaga, Iwona, Priti Parikh, Julia Tomei, and Long Seng To. 2020. "Mapping Synergies and Trade-offs Between Energy and the Sustainable Development Goals: A Case Study of Off-grid Solar Energy in Rwanda”. Loughborough University. https://hdl.handle.net/2134/13207466.v1. 


\title{
Mapping Synergies and Trade-offs Between Energy and the Sustainable Development Goals: A Case Study of Off-Grid Solar Energy in Rwanda
}

\section{Authors}

Iwona Bisaga ${ }^{1 *}$, Priti Parikh ${ }^{1}$, Julia Tomei ${ }^{2}$ and Long Seng To ${ }^{3}$

\section{Affiliation}

${ }^{1}$ Engineering for International Development Centre, UCL Civil, Environmental and Geomatic Engineering Department, University College London, Chadwick Building, London WC1E 6BT, UK

${ }^{2}$ UCL Institute for Sustainable Resources, University College London, 14 Upper Woburn Place, London WC1H ONN, UK

${ }^{3}$ Geography and Environment, Loughborough University, Loughborough LE11 3TU, UK

Corresponding author *Iwona Bisaga

\begin{abstract}
Energy access is crucial for human well-being and poverty reduction. In sub-Saharan Africa, the failure of grid systems to provide electricity access to last mile users has led to the rapid scale up of off-grid solutions. The authors examine synergies and trade-offs between solar off-grid solutions and the Sustainable Development Goals (SDGs) in Rwanda which as a nation has successfully implemented innovative solar off-grid systems at scale. This paper is the first to map the relationship between energy and the 169 Targets of the 2030 Agenda in a specific country and sector context by operationalising the framework developed in FusoNerini et al. (2018). By doing so, this paper demonstrates the need for context-specific rapid assessment tools to monitor and improve energy access. The paper identifies synergies between $80(47 \%)$ of the SDG targets and off-grid solar systems in Rwanda, thus demonstrating the wide-ranging benefits and value added through the inclusion of the off-grid solar energy sector in the electrification strategy. The paper demonstrates how mainstreaming off-grid policies and prioritising investment in the off-grid sector can realise human development and well-being, build physical and social infrastructures, and achieve sustainable management of environmental resources.
\end{abstract}


Keywords: Sustainable Development Goals; off-grid solar; electrification; energy access; Rwanda; synergy and trade-off

\section{Highlights:}

- A rapid assessment methodology for context-specific outcome of off-grid energy

- First in-country case study of linkages between off-grid energy sector and SDGs

- Identified synergies between 80 SDG Targets and off-grid solar systems

- Benefits and impacts from off-grid solar energy are wide-ranging

- Policies prioritising investment in the off-grid sector will help realise the SDGs

\section{Introduction}

In 2015, the 193 Member States of the United Nations (UN) adopted an historic agreement to deliver a thriving, peaceful and sustainable planet by 2030. The UN 2030 Agenda is underpinned by 17 interconnected Sustainable Development Goals (SDGs) with 169 Targets, which provide comprehensive coverage of issues ranging from No Poverty (SDG1) to Partnerships for the Goals (SDG17). SDG7 aims to ensure access to affordable, reliable, sustainable and modern energy for all by 2030 and includes five Targets [1]. This paper focuses on SDG7 through the lens of the off-grid solar energy sector, which is delivering access to electricity in resource-challenged settings where traditional grid solutions have failed to deliver. Some countries, including Rwanda, recognise the potential of off-grid solutions to reach last mile users and have mainstreamed such solutions into policy. 
The SDGs are indivisible - action on one SDG will have interlinkages with multiple others. Thus, the delivery of SDG7 requires an integrated and comprehensive understanding of the linkages between energy and other development goals. Several studies have shown that energy underpins the delivery of the SDGs. Studies include systematic reviews of interactions between all 169 Targets (Weitz et al., 2018), and interactions between specific SDGs and all other Targets or Goals (on energy FusoNerini et al., 2018 and McCollum et al., 2018; on oceans, seas and marine resources Singh et al., 2018, on sanitation Parikh et al., 2020). A standard framework is emerging for assessing the strength of the interactions (Nilsson et al., 2018). However, the large number of possible interactions requires simplification to give rapid results. Some studies have focused on a specific subset of SDGs (Fader et al., 2018; Thacker et al., 2019) or have eliminated Targets at an early stage of analysis (Santika et al., 2018); however, such approaches risk missing synergies and trade-offs. Project-level assessment of linkages between energy and SDGS are complex and especially challenging in data-constrained settings (Castor et al. 2020). Sebestyén et al. (2019) take a data-driven approach to rapidly identify clusters of interaction, but the approach is limited where data is unavailable at country or technology level. Tools that provide a rapid country level assessment are required to support context specific decisionmaking processes and investment.

This paper identifies the multiple linkages between the off-grid solar energy market in Rwanda and the SDGs. It makes an important contribution to the energy and development sectors by applying the more general, high-level frameworks to the localised setting of Rwanda, incorporating contextual barriers and opportunities within the off-grid space where public-private sector partnerships are key to driving innovation. Specifically, the paper uses the methodology developed by the authors in 
Fuso-Nerini et al. (2018) to identify synergies and trade-offs between off-grid solar energy in Rwanda and the 169 Targets of the 2030 Agenda. In so doing, it aims to identify existing evidence and opportunity gaps for mainstreaming off-grid solar energy to achieve a just low carbon transition and support the delivery of sustainable development in Rwanda. The analysis provides important insights to inform future electrification planning and investment decisions for clean energy.

The paper is structured as follows: section 2 provides an overview of the energy sector in Rwanda, with a particular focus on off-grid solar solutions, and the role energy plays

in the UN 2030 Agenda. Section 3 describes the methods used, while section 4 examines the relationship between off-grid solar energy and sustainable development in Rwanda. Section 5 discusses the findings and their implications, while section 6 concludes the paper and offers policy recommendations.

\section{Off-grid solar energy and the UN 2030 Agenda in Rwanda}

Electricity access in Rwanda has increased steadily over the last decade. In 2009, approximately $9 \%$ of households had access to electricity compared to $55 \%$ in 2020 (MININFRA, 2020). Of connected households, $40 \%$ were connected via the national grid, primarily in urban and peri-urban areas, and 15\% via off-grid systems, largely in rural areas (ibid.). Barriers to grid expansion include high upfront costs, especially when trying to reach last mile households, challenging topography, remoteness of rural households, low demand and limited affordability. Under these conditions, offgrid Solar Home Systems (SHSs) and other distributed solutions have the potential to serve unelectrified customers (Bisaga, 2019; Kennedy et al, 2019; Niyonteze et al, 2020). SHS account for a considerable proportion of off-grid connections at approx. $14 \%$ of the total access rate, or over 1.7 million people, with the remaining $1 \%$ of off- 
grid connections through solar mini-grids and lanterns (EnDev, 2019). There are over 20 private providers who signed Memoranda of Understanding (MoU) with the Government of Rwanda (GoR) (REG, 2018). The GoR has built strong partnerships with off-grid solar companies. Through close collaboration and regular consultations with the private sector, tax exemptions on solar products and strong support from partners, such as the Climate Investment Funds (CIF) and Energising Development (EnDev) through its Results-Based Financing (RBF) facility, the Rwandan off-grid solar sector has been among the fastest growing in Africa. Mobile infrastructure, also promoted by GoR, has further enabled solar companies to implement innovative Pay as You Go (PAYG) business models, providing critical financing to households without electricity access, and enabling remote monitoring. This latter allows real time energy consumption data to be collected and used for predicting future energy demand trends, thus informing system design improvements and investment priorities (Bisaga et al., 2017; Bisaga, 2020).

Under the Economic Development and Poverty Reduction Strategy (EDPRS) I and II, efforts to rapidly scale energy access have included the Electricity Access Rollout Programme (EARP) and Sector Wide Approach (SWAp) development project jointly led by the Rwanda Energy Group Ltd (REG) and the World Bank (WB) between 2009 and 2017 (Knight, 2016). The government- owned REG consists of two implementing bodies: the Energy Development Corporation Limited (EDCL) and the Energy Utility Corporation Limited (EUCL), which are responsible for energy development and utility service delivery (REG, 2018). Along with the Ministry of Infrastructure (MININFRA) who deliver the overall infrastructural development in the country, and the Rwanda Utilities Regulatory Authority (RURA), which is tasked with regulating four energy sub- 
sectors (electricity, renewable energy, gas and downstream petroleum), they constitute the key stakeholders in Rwanda's energy sector (RURA, 2020).

It is clear that off-grid energy, and in particular off-grid solar energy, plays an important role in Rwanda's electrification strategy. It encompasses solar lanterns (<10W), SHSs (typically $>10 \mathrm{~W}$ up to $200 \mathrm{~W}$, mostly DC), solar mini-grids (typically between 5 and $300 \mathrm{~kW}$ with bigger systems also possible, AC or DC), solar water pumps, solar water heaters etc. The Rwanda Rural Electrification Strategy (RES) has an ambitious goal to achieve $100 \%$ electrification by 2024 , with $48 \%$ of household connections provided through off-grid solutions (GoR, 2016). Together with the Sustainable Energy for All Action Agenda, they provide the framework for rural electrification through renewable energy (ibid.). The Energy Sector Strategic Plan (ESSP) 2017/18 - 2023/24 outlines the goals for the energy sector in light of the UN 2030 Agenda (GoR, 2018). It prioritises grid extensions under EARP to productive end-users and households within a determined proximity to the existing grid (GoR, 2014). The ESSP also highlights the implementation of off-grid solutions to low-income and low-demand households and assumes a leading role for the private sector. Off-grid solutions for productive uses are also set to be delivered where most optimal, as technological advances now allow for higher generation capacity and more efficient solar panels, as well as solarpowered appliances such as fridges, shavers and incubators (ibid.). A roll out of a country-wide subsidy for SHSs is also currently being planned by the GoR (GoR and REG, 2020). It is therefore important to assess how this emerging market will influence and shape the delivery of the SDGs in Rwanda.

\section{Methods}


This study builds on the global mapping of synergies and trade-offs by Fuso-Nerini et al. (2018) and applies the framework to a specific country context. Our analysis focuses on off-grid solar systems, which includes the production, conversion, delivery and use of off-grid solar energy. As the number of SHSs in Rwanda is considerably higher than the number of connections provided through solar mini-grids ( $390,000 \mathrm{vs}$ $\sim 4,000$ connections (EnDev, 2019)), we focus on the former when assessing the status quo and the latter where their applications are evidenced. We answer two questions: (a) does the SDG Target call for action in relation to off-grid solar systems in Rwanda? and (b) are there synergies and/ or trade-offs between the SDG Target and decisions about off-grid solar systems in pursuit of SDG7 in Rwanda? (see Figure 1).

Using a structured process, we addressed question (a) through a normative, qualitative content analysis of the text of each Target, which established those Targets that call for action in relation to off-grid solar systems in Rwanda. To answer question (b), we first undertook an expert elicitation and then identified empirical evidence of relationships (synergies and trade-offs) between the achievement of each Target and decisions relating to off-grid solar energy in pursuit of SDG7. The lead author carried out the initial mapping exercise to identify evidence for linkages based on a review of policy documents, grey literature, academic papers, extensive fieldwork and in-country experience working in the off-grid solar energy sector in Rwanda. The aim was not to undertake a systematic review of the evidence relevant to each Target, but rather to identify where synergies and trade-offs exist. A single item of published evidence or research data collected was deemed to be sufficient evidence of the existence of a synergy and/ or trade-off (see Appendix A for the complete assessment). However, unlike Fuso-Nerini et al. (2018) this paper also considers policy documents, non-peer 
reviewed grey literature and experiential work to enable a broadening of the evidence base. This was important given the rapid pace of the sector's development and the need to include innovative practices led by the private sector, enabling the authors to incorporate the latest developments from the field which complement (limited) peerreviewed publications. A limitation of this study is the inclusion of only documents published in English.

The initial mapping exercise was reviewed by all co-authors, which was then refined through discussion until a consensus was reached. This validation exercise highlighted a key challenge for the analysis, namely that currently off-grid solar systems in the SHS range have limited capacity to meet higher power energy needs, e.g. for commercial use or industrial production, whereas solar mini-grids, while capable of supporting higher power demand activities, are often challenging economically and require considerable subsidies to offer affordable end-user rates. The limited capacity and other feasibility constraints are therefore considered limitations of these energy systems (rather than trade-offs) and are acknowledged throughout the paper. Additionally, there were several Targets where the authors expected to see synergies and/or trade-offs but no evidence was found to support them. Those Targets are highlighted as potential research gaps to be filled.

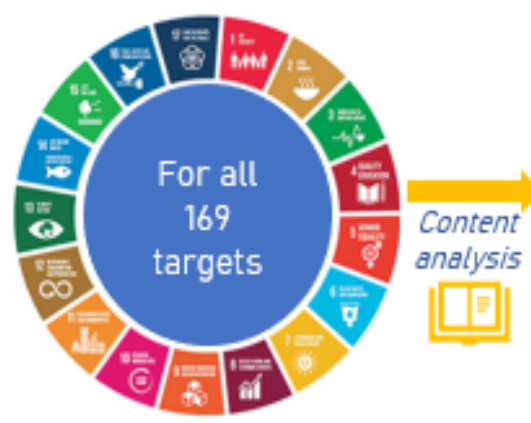

(a) Is there a

call for action in

relation to off-

grid solar

systems? (b) Are there

synergies \&

trade-offs with

off-grid solar

energy?
A map of

synergies \&

trade-offs 
Figure 1. The method of assessing interlinkages between off-grid solar energy systems in Rwanda and the UN 2030 Agenda.

\section{Relationship between off-grid solar energy and sustainable development in}

\section{Rwanda}

Full results of the assessment of off-grid solar energy in Rwanda are presented in the supplementary material and a summary is shown in Figure 2 below.

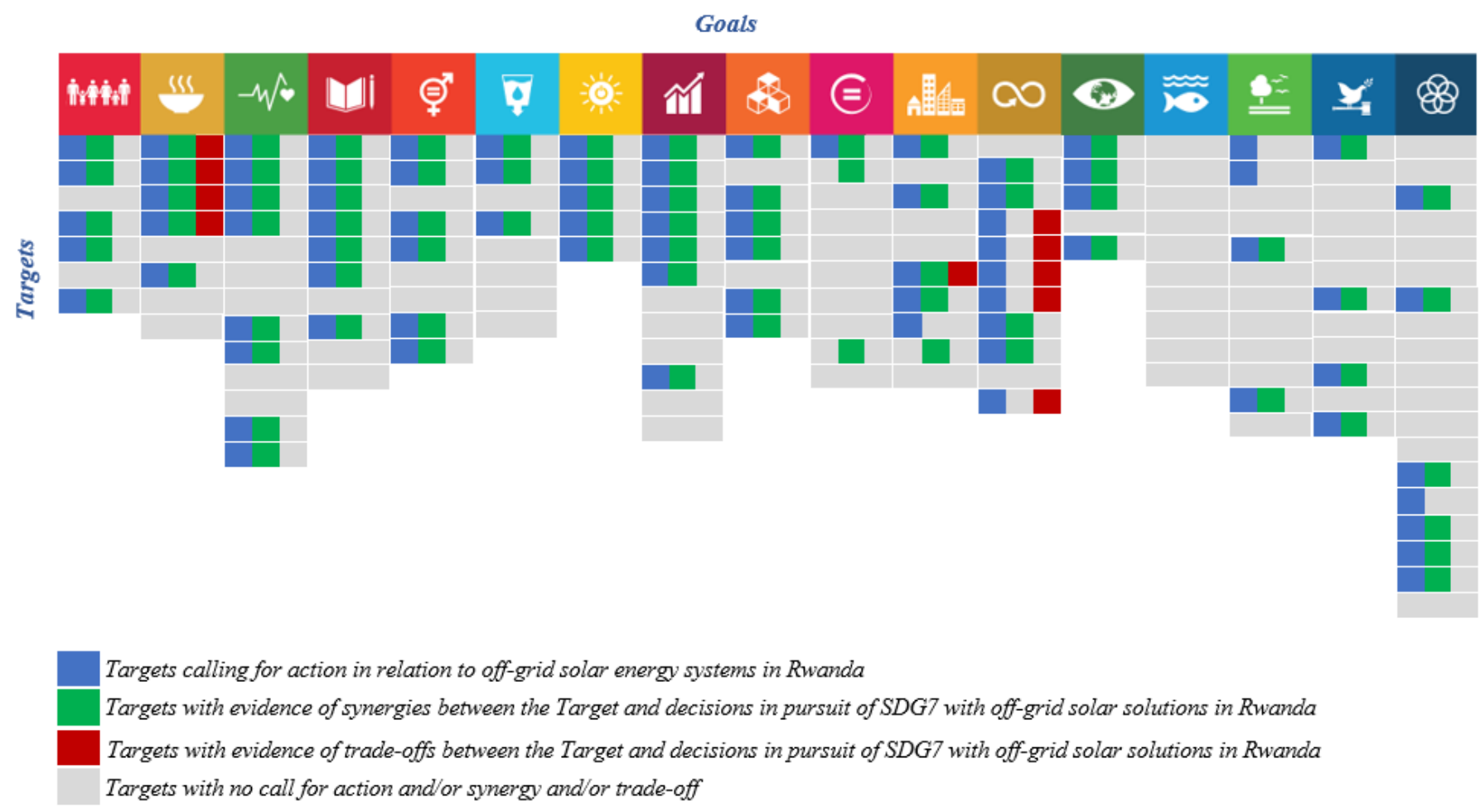

Figure 2. Interlinkages between off-grid solar energy in Rwanda, the SDGs and

Targets. Specific Targets in the UN 2030 Agenda are grouped together under each SDG (listed horizontally). Targets are listed vertically with each row corresponding to a Target. 
Responding to question (a), 86 Targets ( $~ 51 \%)$ require actions to be taken in relation to off-grid solar in Rwanda. The large number of Targets requiring action for off-grid solar highlight the importance of this rapidly expanding sector. The actions identified span all but one Goal, SDG14 (Life Below Water) as Rwanda is a landlocked country with no direct access to marine resources.

With regard to question (b), we identified evidence of synergies and trade-offs between 85 Targets ( 50\%) and off-grid solar systems in Rwanda. There were 80 Targets with synergies and 10 Targets with trade-offs, five Targets had both a synergy and a tradeoff. Most trade-offs relate to SDG2 (Zero Hunger) and SDG12 (Responsible Consumption and Production) for reasons that will be discussed below.

We cluster the results of our study into three groups or domains building on classification frameworks developed by Waage et al. (2015) and Fuso-Nerini et al. (2018). The first domain includes SDGs and their constituent Targets in relation to individual and collective well-being and aspirations (i.e. SDGs 1, 3, 4, 5, 10, 16). The second domain focuses on infrastructure services and delivery to include production and distribution of goods and services using a systems approach (i.e. SDGs 2, 6-9, 11, 12). The third domain includes those focusing on environment and resources (i.e. SDGs 13-15).

\subsection{Aspirations of greater welfare and wellbeing}

Improving the quality of life and economic wellbeing of those living in rural areas is embedded in the GoR approach to rural development, and can be achieved through access to improved infrastructure, including energy (GoR, 2013). The role of off-grid solar solutions in rural development is emphasised not only in the RES (GoR, 2016) but also in the EDPRS (GoR, 2013). Energy, therefore, plays an important role in 
Rwanda's collective aspirations of greater wellbeing and welfare. For off-grid solar energy in Rwanda, we identified 44 Targets with published evidence of synergies and/or trade-offs (44 synergies and 3 trade-offs) under this domain.

SHSs have been shown to improve the physical and economic wellbeing of households by eliminating polluting lighting fuels, such as kerosene (Targets $3.4,11.1$ ) (Bisaga, 2019; Grimm et al., 2016), and by enhancing income-generating opportunities (Targets 1.1, 10.1) (GOGLA, 2019). Additionally, the off-grid solar sector in Rwanda has contributed to job creation (both skilled and unskilled labour) and capacity building (Targets 1.1, 1.2, 9.5, 12.a) (GOGLA, 2019a). SHSs and solar mini-grids have also been deployed in refugee camps across Rwanda, building resilience and access to improved welfare and economic opportunities for vulnerable groups, including women and children (Targets 1.4, 1.5) (Practical Action, 2017). Solar irrigation (Gasore et al., 2015; Hartung and Pluschke, 2018), and to some extent solar cooking (FONERWA, 2013), help boost the harvests of smallholder farmers and food preparation and preservation for improved access to fresh and nutritious food (Targets 2.1, 2.2, 8.2). However, under these Targets potential trade-offs have been identified due to: the possibility of competition for land between agriculture and land required for mini-grids; and, at a household level, competition between access to modern energy and food as households prioritise the most critical necessities. Moreover, the limited capacity of off-grid solar systems poses a limitation on the use of higher power agricultural appliances, which may limit the contribution of off-grid solar to the delivery of some Targets (e.g. Target 2.3).

Off-grid solar solutions in Rwanda are also crucial for achieving healthy lives and promoting wellbeing at both household and community levels (Targets 3.1-3.4, 3.9). 
Such solutions have helped reduce indoor air pollution by reducing the use of fuels such as kerosene (Target 13.3) (WHO, 2016). Solar energy solutions have been deployed in clinics, enabling safe storage of medicines and vaccines (Target 3.8) (WHO and World Bank, 2015). Trade-offs with achieving universal health coverage (Target 3.8) might result from households choosing to pay for solar energy over paying for health insurance. However, new or improved income streams stemming from access to energy (Moore et al., 2020) might also be channeled towards healthcare. Extended hours of light in the evening and a safer learning environment thanks to solar applications enable children to study more and increase their chances of higher educational achievements (Targets 4.1, 4.2, 4.5, 4.6) (Bisaga, 2019; Collings and Munyehirwe, 2016). The off-grid solar sector also offers and creates demand for vocational training and technical capacity building (Targets 4.3-4.6, 8.3, 8.5, 8.6) (Africa-EU Renewable Cooperation Programme, 2014). In off-grid households, solar energy equips women with the ability to have more flexible schedules, relieving them of burdensome activities (such as travelling long distances to collect or purchase fuel) and to do more work outside of home during the day, as well as offering improved feeling of safety at night due to a well-lit environment (Bisaga, 2019). The off-grid solar energy sector has also created female-led microenterprises in Rwanda and improved access to information technology for women (Targets 5.1-5.5, 5.b), thus also reducing inequalities (ENERGIA, 2019; CIF, 2015). Furthermore, gender mainstreaming is applied in Rwanda's energy policies with the aim of promoting gender inclusion and participation of women in the energy sector (Targets 5.c, 10.2) (GEG Africa, 2018). Finally, off-grid solar energy enhances individual and collective wellbeing by building peaceful and inclusive societies through: enabling safer living environments (Target 11.1); providing equal opportunities for everyone to access information and 
communication technology (ICT) and connecting people to the world beyond their locality (Target 9.c); and, including women in decision-making regarding energy access and wider socio-economic development (Target 5.5).

\subsection{Physical and social infrastructures}

Access to both physical and social infrastructure plays an important role in contributing to poverty alleviation and is embedded within Rwanda's EDPRS (GoR, 2013). Whether world class physical infrastructure or cultivation of home-grown solutions, such as umuganda and girinka[3], the provision of such infrastructures is explicitly incorporated into Rwanda's Vision2020 and underpin aspirations for greater welfare and wellbeing of its citizens. Our assessment reveals that there is evidence of 58 Targets with synergies and/or trade-offs under this domain ( 57 synergies and 5 tradeoffs).

Delivering SDG2 (Zero Hunger) relies on energy to power agricultural equipment for efficient and sustainable food production. Off-grid solar energy contributes to this Goal through solar irrigation which facilitates clean energy-based, year-round food cultivation (Rutibabara, 2018; FAO, 2015; Gasore et al., 2015; Nshimyumuremyi, 2015; Safari, 2010) and reducing the risk of food insecurity (Targets 2.1, 2.3, 2.4). Technologies such as solar cookers can have an impact on improved nutrition and have been tested in Rwanda's Eastern Province (FONERWA, 2013; SURF Survivors Fund, 2013) (Target 2.2). However, SDG2 also demonstrates some trade-offs [4] with SDG7 through the potential competition between land required for crops and solar mini-/micro-grid development, as well as groundwater depletion due to increased solar irrigation (Targets 2.1 to 2.4 ). 
Off-grid solar energy has a critical role to play in the achievement of SDG3 (Good Health) by supporting access to electricity in health centres to provide sustained access to medical equipment in areas with no or unreliable grid connections (Partners in Health, 2007; WHO and World Bank, 2015; World Bank, 2017) (Targets 3.1 - 3.3).

Access to information through mobile phones, televisions or radios and access to early-warning systems requires electricity and off-grid solar systems have been providing access in rural, often remote villages (EnDev, 2019; REMA, 2010) (Target 3.d). Off-grid solar solutions can also enhance community and household resilience, not only by connecting them to information, but also by enabling independence of grid networks that are more susceptible to disasters (SDG9) and connecting places where traditional infrastructure does not reach, such as refugee camps (SDGs 1, 3, 9) (Practical Action, 2017). Similarly, off-grid solar energy has a significant role to play in enabling access to quality education and supporting life-long learning for all. For example, by improving school facilities and living environments which support enhanced student performance (Targets 4.1, 4.2, 4.5, 4.6) (Bisaga, 2019; Collings and Munyehirwe, 2016; European Union, 2018). The growth of the off-grid solar sector has also created demand for solar energy vocational courses, which have gradually entered the Rwandan curriculum at universities and vocational training centres (Targets 4.3, 4.4) (Africa-EU Renewable Energy Cooperation Programme, 2014).

In Rwanda, the off-grid solar sector has created new economic opportunities by facilitating access to clean electricity and enabling productive uses of energy for men and women (Target 8.3) (IRENA, 2018; World Bank, 2017). It has also enabled endusers to build their credit profiles for improved financial inclusion (SDG8) (GSMA, 2017) and has facilitated the spread of mobile money (SDG9). The mobile money 
sector has also contributed to job creation in Rwanda, including in secondary sectors (e.g. logistics or real estate) which have either grown or emerged as a result of the scale up of the off-grid solar sector (Targets 8.5, 8.6) (GOGLA, 2019a).

Off-grid solar infrastructure can further enhance efforts that support SDG11 (Sustainable Cities and Communities), for example in informal settlements which may have limited energy access, and in improving the environmental footprint of cities (SDG13) (REMA, 2011). Finally, the off-grid solar energy sector's contribution towards SDG17 (Partnerships) has been significant due to the creation of Public-Private Partnerships (PPPs) between the GoR and private solar providers which have enabled the roll out of off-grid solar systems (see box below). Such systems have also involved participation of local and international stakeholders, including development partners, (international) non-governmental organisations ((I)NGOs) and practitioners, for the benefit of collectively enabling sustainable development across Rwanda (EUEI, n/d). There is also a knock-on impact on investment in the energy sector to other physical infrastructures, such as water where solar water pumping, distribution and smart metering of consumption is dependent on energy systems. This, in turn, can positively impact the agriculture sector and incomes as improved and reliable access to water leads to improved food security and livelihood opportunities for smallholder farmers (Dalberg \& Efficiency for Access Coalition, 2019). By interconnecting SHSs through smart energy management to create SHS-based mini-grids, the technology has the potential to include higher-power appliances, such as refrigerators, serving urban as well as peri-urban and rural customers (Soltowski et al., 2019).

\subsection{The environment and natural resources}


Rwanda's goals include not only a decrease in dependency on natural resources, but also mainstreaming of environmental sustainability in social and commercial sectors (GoR, 2013). Under this domain, there are 21 Targets with synergies and trade-offs between off-grid solar energy and SDG7 (17 synergies and 6 trade-offs).

Off-grid solar systems are a clean energy source which means their use increases the share of renewables in the Rwandan energy mix (Target 7.2). Such systems contribute to reducing exposure to climate change-related shocks through the reduction in use of kerosene, candles or wood, eliminating hazardous indoor pollution and related illnesses or deaths (Target 3.9) and making them a feasible solution for combating climate change and conserving inland resources (Target 13.2, 13.3, 13.b) (Bisaga, 2019; GoR, 2011). However, off-grid solar solutions focus primarily on electricity rather than cooking, and as yet do little to address demand for firewood (World Bank, 2014), although some solar companies in Rwanda are exploring solar cooking solutions (Target 7.1).

Through the expansion of the range of super energy efficient appliances, which can support an ever wider set of productive activities, off-grid solar energy helps achieve resilient and sustainable industrialisation (SDGs 8, 9, 12), particularly through the application of solar mini/micro-grids. This has been achieved by fostering innovation, not only through technological and engineering advancements, but also through innovative business models (SDG9) (Bisaga, 2020; Kizilcec and Parikh, 2020).

Through solar irrigation, off-grid solar energy offers the opportunity for sustainable crop production and management of water resources (Targets $2.4,6.4$ ). By supporting productive activities, off-grid solar energy systems can boost economic growth without negatively impacting the environment (Target 8.4). However, potential trade-offs 
concern sustainability of resource extraction and procurement for the production of offgrid solar system components (particularly panels and batteries) and solid waste management of solar waste at the end of its life (Targets 12.4-12.7, see box below) (Magalini et al., 2016). The scale-up of the solar market in Rwanda will need to be supported with robust policies and systems for safe disposal and reuse of solar panels, batteries and other components. A notable example has been the GoR's E-Waste Bill which generally makes the producer responsible for e-waste disposal and has set up a 10,000 tonnes/year dismantling plant near the capital Kigali in order to facilitate the collection and recycling of solar waste. Lithium-phosphate batteries found in pico-solar products have been found to have a negative net treatment cost whereas lead-acid battery SHSs have been assessed as potentially zero net cost due to the intrinsic value of lead, thus covering the cost of collection and treatment (Sinha Khetriwal et al., 2017). Despite high levels of investment into the off-grid solar sector in Rwanda, a more explicit inclusion of e-waste collection and recycling requirements will be needed to address the growing number of end-of-life solar products.

\section{Discussion}

The study identified synergies and trade-offs between off-grid solar energy in Rwanda and Goals and Targets of the UN 2030 Agenda. The off-grid solar energy sector in Rwanda has synergistic links with 16 out of the 17 SDGs demonstrating the wideranging benefits of partnerships and investments. The assessment revealed that offgrid solar in Rwanda has synergies with 85 of the 169 Targets (i.e. 50\%), highlighting the vital contribution the sector makes to electrification and broader development efforts in the country. Figure 3 below shows a comparison of the mapping results for all energy systems globally (from Fuso-Nerini et al. 2018) and the off-grid solar energy 
systems in Rwanda. While overall there are fewer synergies, the number of trade-offs is significantly lower, making it an appealing clean energy solution to address developmental challenges.

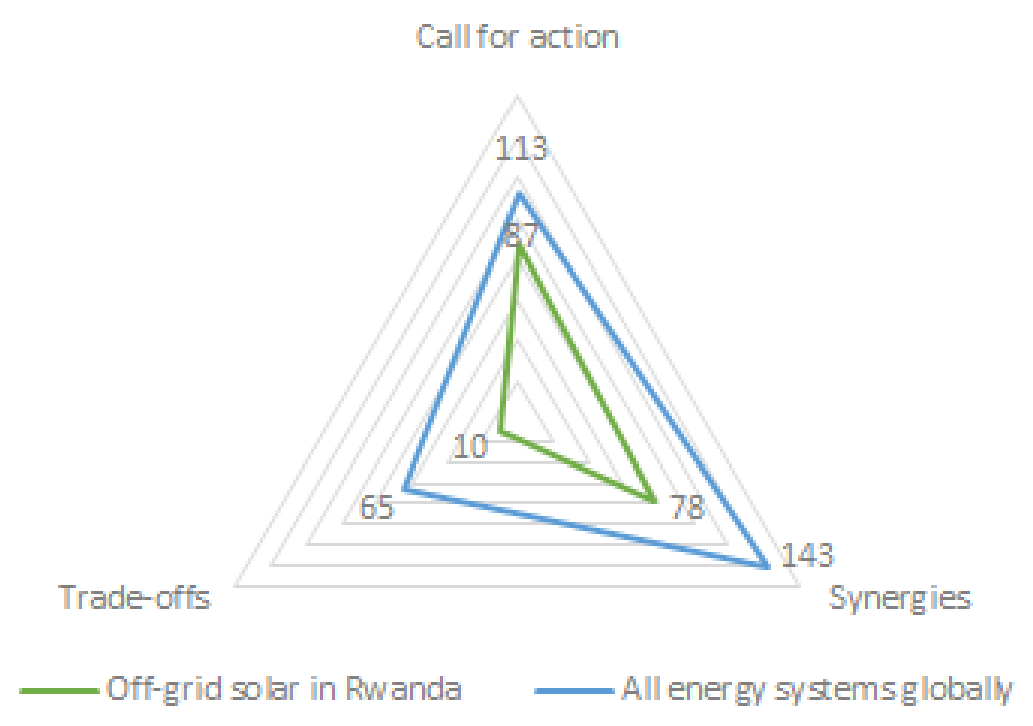

Figure 3. Comparison of mapping results (calls for action, synergies and trade-offs) for all energy systems globally (Fuso-Nerini et al. 2018) and for the off-grid solar energy in Rwanda.

Of key importance to the success of off-grid solar in Rwanda has been the government's continued support for, and recognition of, energy as an enabler of development. Benefitting from the provision of an enabling environment, the off-grid solar sector has made a significant impact on the increase in electricity access, especially in remote rural communities. Low-income households with limited capacity to pay for a grid connection have been able to reap benefits from innovations in the sector, such as PAYG solutions. The private sector has been instrumental in developing innovative business models for low-income households who consume 
small amounts of energy. The challenge moving forward will be around affordability and availability of those services requiring further policy support, perhaps including subsidies (e.g. Nash \& Khinmaung-Moore, 2020). Rwanda has provided a useful case study for this SDG mapping exercise since it illustrates how a modern, clean energy technology, underpinned by a supportive policy framework, with a holistic approach covering energy and infrastructure, agriculture, climate, public health and economic growth, and cross-sectoral partnerships can be integral to a country's development efforts ${ }^{1}$. Such a perspective helps to ensure that energy is viewed not in a silo, but rather as fundamental to a country's sustainable development.

The analysis also highlights the two-way relationship between SDG7 and other SDGs, wherein SDG7 underpins the achievement of all other SDGs and vice versa. However, the mapping has demonstrated that there are some Goals which have yet to benefit from off-grid solar applications in Rwanda, particularly SDG11. As argued elsewhere (Castan-Broto et al., 2017) there are ample opportunities for off-grid energy solutions to support the achievement of SDG11 and SDG13; for example, by reducing cities' emissions, increasing energy resilience, and addressing the electrification gap in informal, off-grid settlements. Often it is assumed that proximity to grids in cities implies access to energy, but settings such as informal settlements in urban centres may remain off-grid. Plugging this gap requires continued support for and strategic investment in the off-grid solar sector in such challenging settings. It also requires cross-sectoral and transdisciplinary collaboration in order to ensure synergies and trade-offs between energy and other SDGs are not overlooked.

\footnotetext{
${ }^{1}$ See references and Appendix A for relevant policy documents cited in this publication (highlighted in purple in Appendix A).
} 
A paucity of context-specific peer review publications on the off-grid solar energy sector in Rwanda necessitated the inclusion of diverse non-peer reviewed sources of data. This will be a challenge for many rapidly evolving fields - not just energy access - where finance, technology and policy must adapt and innovate to challenging local conditions. Inclusion of different forms of evidence will also be required in countries where published scientific evidence is relatively scarce, making it challenging to assess the strength of the identified synergies. Adaptability and clarity in terms of identifying relevant evidence is therefore critical for future applications of the framework to specific technology or country cases, as well as deep understanding of the local context in which the mapping is undertaken.

Despite the inclusion of a broader evidence base, the assessment revealed a number of gaps in the literature within themes such as resilience building, disaster risk reduction, cooling technologies, and intra-household decision making, where the authors expected to find synergies and trade-offs. The academic literature primarily examines questions of impact, affordability and suitability of off-grid solutions, as well as the energy access policy environment in Rwanda, but currently lacks focus on the areas identified here as research gaps. The rapidly expanding off-grid solar market presents a challenge for slower burn academic research and highlights a need for faster dissemination channels. If off-grid solar in Rwanda is to deliver the wide range of benefits identified in this analysis, more research is required to inform industry standards and guidelines, and to support technological, market and social innovation. The assessment also identified several limitations of SHSs, many of which are a function of the current state of the art, such as system size, price and thus affordability. The framework has helped to identify opportunities for R\&D investment, such as battery life and sizing, materials and technology in conjunction with innovative 
business models. The assessment also highlights that there are few trade-offs with off-grid solar in the environment domain due to reduced use of biomass and kerosene. However, the safe disposal and reuse of solar panels and associated parts must be an integral part of planning the scale up of off-grid solar systems in Rwanda and elsewhere where there has been a similar level of integration of off-grid solar solutions into the national electrification strategy. Consistent and transparent standards for the sector will have to be developed, not only for the disposal of end of life or faulty products, but also for energy efficient appliances which can help users maximise the benefits of accessing modern energy, going beyond basic services.

\section{Conclusions and policy implications}

This research has demonstrated the wide-ranging impacts of the off-grid solar energy sector in Rwanda. These extend far beyond the provision of electricity to off-grid households and communities, to diverse sectors such as water, agriculture, education and health. This finding supports growing evidence of the key role that energy plays in delivery of the UN 2030 Agenda and the ability of the off-grid solar sector to power communities currently bypassed by conventional grid solutions. This study also makes the case for targeted action in the off-grid sector not only to meet SDG7 but also to leverage the wide-ranging benefits across 16 out of 17 SDGs.

The GoR's creation of an enabling environment has not only resulted in positive impacts on electricity access and the rapid growth of the off-grid solar sector, but has supported development gains in numerous other sectors. However, further development of the sector will likely require additional measures. For example, extended solar applications to urban settings and to productive uses may require more tailored interventions. Issues concerning solar waste may have to be coded in policy 
in order to expand the already robust off-grid solar energy framework and ensure adequate treatment of the systems throughout their lifetime. Further, for the most marginalised groups, such as refugees and households living in poverty, subsidies could be considered to enable energy access. This requires cross-sectoral partnerships between public and private sectors to help deliver innovative and affordable models for energy delivery. The policy environment in Rwanda has been conducive to private sector involvement in the off-grid space. Moving forward, especially in the post-COVID era, affordability at household level will be a challenge with loss of livelihoods and targeted interventions will be required to prevent households from experiencing energy poverty.

The framework developed by Fuso-Nerini et al. (2018), and applied here to off-grid solar in Rwanda, has potential for use as a rapid assessment tool to further the identification of current and future opportunities and challenges of off-grid solar solutions and broader efforts in energy access provision. This tool could also be used to monitor progress and evaluate policies aimed at enhancing energy access and attainment of other SDGs. However, in order to facilitate such assessments, availability of timely and appropriate evidence will be crucial and herein lies a key challenge for academic research. Namely that in rapidly changing contexts, characterised by dynamic, market-based approaches and innovative public and private sector delivery models, it is difficult for slower burn research and dissemination to keep abreast of developments in a timely manner.

Stronger collaboration between industry and academia are required to harness joint research opportunities and bring innovative practices to the forefront. For example, moving forward there will be a need for an improved understanding of user needs and 
aspirations, current and likely future energy consumption trends and spending patterns for better system battery sizing, design of appliances and pricing plans. Private providers will also benefit from more targeted research inputs to support sustained growth, develop projects on future market demand based on observed end-user needs, and strengthen knowledge gaps in the relatively novel off-grid solar sector. In return, data and sharing of the on-the-ground challenges by providers would make a valuable addition to knowledge and fill some of the existing evidence gaps. Policymakers have a key role in facilitating data sharing and collaboration between industry and academia by making available innovation funding mechanisms, providing partnership brokerage services and mandating standardised formats for data reporting.

The paper offers important insights for policymakers in Rwanda and paves the way for similar assessments in other developing countries to better understand the synergies and trade-offs between off-grid solar energy systems (or another subset of energy systems) and the SDGs, and identify evidence gaps. For policymakers, the wideranging co-benefits of electricity access and off-grid solar that have been identified through this assessment highlight the cross-sectoral nature of energy access. If the full range of benefits are to be realised, collaboration will be required between different ministries and at different levels of government i.e. national, regional and local. Rwanda, through its imihigo framework and joint performance targets among ministries and other high-level administrative bodies, provides an example of good practice in cross-ministerial collaboration. The need for integration and crossstakeholder collaboration echoes the call by Brown et al. (2018) for policymakers to engage with research in order to generate both data and evidence for effective decision making. 
Finally, the identification of synergies and trade-offs between action on SDG7 and the UN 2030 Agenda will help to focus attention on people, communities and sectors most at risk of being disadvantaged or left behind by current approaches. Further, and by adopting a wider definition of evidence, this assessment has shown how perspectives from diverse sources can be integrated with the scientific literature to create a more holistic map of the interactions between off-grid solar energy and the SDGs. This is vital for settings and challenges where data is scarce or unavailable and lags behind rapidly evolving on-the-ground developments. This paper paves the way for low-resource, country-level assessments of the impact of various sectors on delivery of the SDGs, thereby providing valuable insights for multiple stakeholders as they accelerate action towards the UN 2030 Agenda.

\section{References}

Africa-EU Renewable Energy Cooperation Programme (2014). Vocational Training for Renewable Energy in Africa Developing the next generation of energy professionals. Available at:

http://www.eueipdf.org/sites/default/files/field publication file/RECP Vocational Training for Renewable Energy final.pdf [Accessed: 26 July 2019].

Bisaga I. (2020). Innovation for Off-Grid Solar Rural Electrification. In: Leal Filho W., Azul A., Brandli L., Lange Salvia A., Wall T. (eds) Affordable and Clean Energy. Encyclopedia of the UN Sustainable Development Goals. Springer, Cham.

Bisaga, I. (2019). Scaling up off-grid solar energy access through improved understanding of customers' needs, aspirations and energy use of decentralised (SMART) Solar Home Systems - a case study of BBOXX customers in Rwanda. University College London PhD Thesis. Available at: http://discovery.ucl.ac.uk/10069395/ [Accessed: 26 July 2019]. 
Bisaga, I., Parikh, P., Mulugetta, Y. and Hailu, Y. (2018). The potential of performance targets (imihigo) as drivers of energy access planning and extending access to off-grid energy in rural Rwanda.WIREs Energy and Environment 2018;e310, pp. 1-14.

Brown, E., Campbell, B., Cloke, J., To, L.S., Turner, B. and Wray, A. (2018). Low carbon energy and international development: from research impact to policymaking. Contemporary Social Science 13, pp. 112-127.

Castor, J., Bacha, K. and Fuso-Nerini, F. (2020). SDGs in action: A novel framework for assessing energy projects against the sustainable development goals. Energy Research \& Social Science, 68(2020), 101556.

Climate Investment Funds (CIF) (2015). Scaling up Renewable Energy Programme (SREP) Investment Plan for Rwanda. Available at:

https://www.climateinvestmentfunds.org/sites/cif enc/files/meetingdocuments/srep 1 47 rev1 srep investment plan for rwanda final revised.pdf [Accessed: 26 July 2019].

Collings, S. and Munyehirwe, A. (2016). Pay-as-you-go solar PV in Rwanda: evidence of benefits to users and issues of affordability. Decentralized Electrification and Development. Special Issue 15, pp. 94-103.

Dalberg and Efficiency for Access Coalition (2019). Solar Water Pump Outlook 2019: Global Trends and Market Opportunities. Available at: https://storage.googleapis.com/e4a-website-assets/Solar-Water-Pump-Outlook2019.pdf [Accessed: 22 October 2020]. 
ENERGIA (2019). Female microenterprise creation and business models for private sector distribution of low-cost off-grid LED lighting: Multiple Randomized Experiments. Available at:

https://www.energia.org/cm2/wpcontent/uploads/2019/04/RA5-Femalemicroenterprise-creation.pdf [Accessed: 26 July 2019].

Energising Development (2019). Rwanda. Off-grid Sector Status Report 2018. Update August 2019.

European Union - Delegation of the European Union to Rwanda (2018). Prepaid Energy. Rent to own solar home systems (off-grid). Available at: https://eeas.europa.eu/delegations/rwanda/47538/prepaid-energy-rent-own-solarhome-systems-grid_en [Accessed: 27 July 2019].

Fader, M., Cranmer, C., Lawford, R., and Engel-Cox, J. (2018). Toward an Understanding of Synergies and Trade-Offs Between Water, Energy, and Food SDG Targets. Frontiers in Environmental Science, 6 (2018).

https://doi.org/10.3389/fenvs.2018.00112.

FONERWA (2013). Solar Cooker Project in the Eastern Province of Rwanda. 20132015 Project. Available at: http://www.fonerwa.org/backend/content/solar-cookerproject-eastern-province-rwanda [Accessed: 27 July 2019].

Food and Agriculture Organization (FAO) of the United Nations (2015). Support for Enhancing Small scale irrigation technologies in Rwanda. 2015-2017 project. Available at: http://www.fao.org/rwanda/programmes-and-projects/project-list/en/

Fuso Nerini, F., Tomei, J., To, L.S., Bisaga, I., Parikh, P., Black, M., Borrion, A., Spataru, C., Castan Broto, V., Anandarajah, G., Milligan, B. and Mulugetta, Y. 
(2018). Mapping synergies and trade-offs between energy and the Sustainable Development Goals. Nature Energy, PersPective, pp. 10-15.

https://doi.org/10.1038/s41560-017-0036-5.

Global Economic Governance (GEG) Africa (2018). Gender mainstreaming in the solar energy sector in Rwanda. Case Study. Vanguard Economics, GEG Africa and SAIIA Resource.

Gasore, G., Munyaneza, J., Ngendabanga, J. P. and Twibanire, A. (20150. Design of Automatic Irrigation System for Small Farmers in Rwanda. Agricultural Sciences, 6(2015), pp. 291-294.

Global Off-Grid Lighting Association (GOGLA) (2019). Powering Opportunity. Report. Available at:

https://www.gogla.org/sites/default/files/resource docs/powering opportunity in eas $\underline{t}$ africa.pdf [Accessed: 21 September 2019].

Global Off-Grid Lighting Association (GOGLA) (2019a). Off-Grid Solar. A Growth Engine for Jobs. Available at:

https://www.gogla.org/sites/default/files/resource docs/gogla off grid solar a growt h engine for jobs web opt.pdf [Accessed: 21 September 2019].

Government of Rwanda (GoR) (2011). Green Growth and Climate Resilience National Strategy for Climate Change and Low Carbon Development. Available at: https://greengrowth.rw/wp-content/uploads/2018/11/Rwanda-Green-Growth-andClimate-Resilience-Strategy.pdf [Accessed: 26 July 2019].

Government of Rwanda (GoR) (2013). Economic Development and Poverty Reduction Strategy II 2013-2018. Available at: 
http://www.minecofin.gov.rw/fileadmin/templates/documents/NDPR/EDPRS 2.pdf [Accessed: 27 July 2019].

Government of Rwanda (GoR) Ministry of Infrastructure (MININFRA) (2014).

Sustainable Energy for All Rapid Assessment and Gap Analysis. Government of Rwanda, Kigali.

Government of Rwanda (GoR) Ministry of Infrastructure (MININFRA) (2016). Rural Electrification Strategy. Available at:

http://www.mininfra.gov.rw/fileadmin/user upload/aircraft/Rural Electrification Strate gy.pdf [Accessed: 27 July 2019].

Government of Rwanda (GoR) Ministry of Infrastructure (MININFRA) (2018). Energy Sector Strategic Plan 2018/19 - 2023/24. Available at:

http://www.mininfra.gov.rw/fileadmin/user upload/infos/Final ESSP.pdf [Accessed: 27 July 2019].

Government of Rwanda (GoR) Ministry of Infrastructure (MININFRA) (2019). Energy. Available at: http://www.mininfra.gov.rw/index.php?id=312 [Accessed: 27 July 2019].

Government of Rwanda (GoR) and Rwanda Energy Group (RED) (2020). Rwanda Energy Access and Quality Improvement Project (EAQIP). Final Report. Stakeholder Engagement Plan (SEP). GoR, Kigali.

Grimm, M., Lenz, L., Peters, J. and Sievert, M. (2016). Demand for Off-Grid Solar Electricity: Experimental Evidence from Rwanda. IZA Institute of Labor Economics Discussion Paper Series, IZA DP No. 10427, pp. 1-33. 
GSMA (2017). Mobile for Development Utilities: Lessons from the use of mobile in utility pay-as-you-go models. Available at:

https://www.gsma.com/mobilefordevelopment/wp-content/uploads/2017/01/Lessonsfrom-the-use-of-mobile-in-utility-pay-as-you-go-models.pdf [Accessed: 27 July 2019].

Hartung, H. and Pluschke, L. (2018). The benefits and risks of solar-powered irrigation- a global overview. Food and Agriculture Organization (FAO) of the United Nations and Deutsche Gesellschaft fur Internationale Zusammenarbeit. Available at: http://www.fao.org/3/i9047en/l9047EN.pdf [Accessed: 27 July 2019].

International Renewable Energy Agency (IRENA) (2018). Off-grid Renewable Energy Solutions. Available at: https://www.irena.org//media/Files/IRENA/Agency/Publication/2018/Jul/IRENA_Offgrid_RE_Solutions_2018.pdf [Accessed: 27 July 2019].

Kennedy, R., Numminen, S., Sutherland, J. and Urpeleinen, J. (2019). Multilevel customer segmentation for off-grid solar in developing countries: Evidence from solar home systems in Rwanda and Kenya. Energy, 186(November 2019), 115728.

Kizilcec, V. and Parikh, P. (2020). Solar Home Systems: A comprehensive literature review for Sub-Saharan Africa. Energy for Sustainable Development, 58(October 2020), pp. 78-89.

Magalini, F., Sinha Khetriwal, D., Rochat, D., Huismann, J., Munyambu, J., Oliech, J., Chidiabsu, I., and Mbera, O. (2016). Electronic waste (e-waste) impacts and mitigation options in the off-grid renewable energy sector. Technical Report: DOI: 10.12774/eod_cr.august2016.Magalinifetal. 
McCollum, D.L., Echeverri, L.G., Busch, S., Pachauri, S., Parkinson, S., Rogelj, J., Krey, V., Minx, J.C., Nilsson, M., Stevance, A.S., and Riahi, K. (2018). Connecting the sustainable development goals by their energy inter-linkages. Environmental Research Letters (13), 033006. https://doi.org/10.1088/1748-9326/aaafe3.

Moore, N., Glandon, D., Tripney, J., Kozakiewicz, T., Shisler, S., Eyres, J., Zalfou, R., Leon, M.D.A., Kurkjian, V., Snilstveit, B. and Perdana, A. (2020). Effects of Access to Electricity Interventions on Socioeconomic Outcomes in Low- and MiddleIncome Countries. Systematic Review Report. Available at:

https://www.adb.org/sites/default/files/evaluation-document/515326/files/in242-20.pdf [Accessed: 23 October 2020].

Nash, S. and Khinmaung-Moore, J. (2020). Designing Sustainable Subsidies to Accelerate Universal Energy Access. Available at:

https://learn.tearfund.org/ /media/files/tilz/climate and energy/2020-tearfunddesigning-sustainable-subsidies-en.pdf [Accessed: 22 October 2020].

Nilsson, M., Chisholm, E., Griggs, D., Howden-Chapman, P., McCollum, D., Messerli, P., Neumann, B., Stevance, A., Visbeck, M., and Stafford-Smith, M. (2018). Mapping Interactions between the Sustainable Development Goals: Lessons Learned and Ways Forward. Sustainability Science, 13(6), pp. 1489-1503. https://doi.org/10.1007/s11625-018-0604-z.

Niyonteze, J.D.D., Zou, F., Asemota, G.N.O., Bimenyimana, S. and Shyiambere, G. (2020). Key technology development needs and applicability analysis of renewable energy hybrid technologies in off-grid areas for the Rwanda power sector. Heliyon, 6(1), January 2020, e03300. 
Nshimyumuremyi, E. (2015). Solar Water Pumping System in Isolated Area to Electricity: The Case of Mbirizi Village (Rwanda). Smart Grid and Renewable Energy, 6(2), pp. 27-39.

Partners in Health (2007). SELF help brings solar power to PIH clinics in rural Rwanda. Available at: https://www.pih.org/article/self-help-brings-solar-power-to-pihclinics-in-rural-rwanda [Accessed 26 July 20019].

Practical Action (2017). Renewable Energy for Refugees. Available at: https://practicalaction.org/renewable-energy-for-refugees and https://www.unitar.org/ptp/sustainable-energy [Accessed 26 July 20019].

Parikh, P., Diep, L., Hofmann, P., Tomei, J., Campos, L., Teh, T-H., et al. (n/d). Mapping Synergies and Trade-offs between Sanitation and the Sustainable Development Goals. Submitted to Lancet Planet Health.

Rwanda Utilities Regulatory Authorities (RURA) (2020). Overview - Energy. Available at: https://rura.rw/index.php?id=137 [Accessed 20 August 2020].

Rutibabara, J.B. (2018). Environmental and Economic Cost Analysis of a Solar PV, Diesel and hybrid PV-Diesel water Pumping Systems for Agricultural Irrigation in Rwanda: Case study of Bugesera District. Master Dissertation, Pan-African University Institute of Water and Energy Sciences. Available at: http://repository.pauwescop.net/bitstream/handle/1/241/Jean\%20\%20Baptiste\%20RUTIBABARA.pdf?seque $\underline{\text { nce }=1 \text { \&isAllowed }=y}$ [Accessed 20 August 2020].

Rwanda Agriculture Board (RAB) (n/d). The One Cow per Poor Family Program (Girinka) in Rwanda. Available at: 
http://rab.gov.rw/fileadmin/user upload/Animal Production/girinkaa pamphlet engl2.pdf [Accessed 22 September 2019].

Rwanda Energy Group (REG) (2019). Electricity access rate reaches 51\%, from 10\% in 9 years. Available at: http://www.reg.rw/media-center/news-

details/news/electricity-access-rate-reaches-51-from-10-in-9-years/ [Accessed 22 September 2019].

Rwanda Environment Management Authority (REMA) (2010). Assessment of Operational Framework Related to Climate Change in Rwanda. Available at: https://www.rema.gov.rw/rema_doc/Climate\%20change/Final_Report_CC_Dpt.pdf [Accessed 26 July 20019].

Rwanda Environment Management Authority (REMA) (2011). Green Growth and Climate Resilience. National Strategy for Climate Change and Low Carbon Development. Available at: https://www.rema.gov.rw/ remagov/rema_doc/RGG\&CRS\%202011/Rwanda\%20Gre en\%20Growth\%20Strategy\%20FINAL\%20high\%20res.pdf [Accessed 22 September 2019].

Safari, B. (2010). A review of energy in Rwanda. Renewable and Sustainable Energy Reviews, 14(1), pp. 524-529.

Sebestyén, V., Bulla, M., Rédey, A., and Abonyi, J. (2019). Network Model-Based Analysis of the Goals, Targets and Indicators of Sustainable Development for Strategic Environmental Assessment. Journal of Environmental Management, 238 (2019), pp. 126-35. https://doi.org/10.1016/j.jenvman.2019.02.096. 
Singh, G. G., Cisneros-Montemayor, A.M., Swartz, W., Cheung, W., Guy, J.A., Kenny, T., McOwen, C.J. et al. (2018). A Rapid Assessment of Co-Benefits and Trade-Offs among Sustainable Development Goals. Marine Policy, 93(July 2018), pp. 223-31. https://doi.org/10.1016/j.marpol.2017.05.030.

Sinha Khetriwal, D., Magalini, F. and Mugabo, C. (2017). Sustainable Management of E-Waste in the Off-Grid Renewable Energy Sector in Rwanda. Energy Africa Compact - Rwanda. Evidence on Demand, United Kingdom Department for International Development.

Soltowski, B., Campos-Gaona, D., Strachan, S. and Anaya-Lara, O. (2019). BottomUp Electrification Introducing New Smart Grids Architecture- Concept Based on Feasibility Studies Conducted in Rwanda. Energies, 12(12), 2439.

SURF Survivors Fund (2013). Solar Cooking. Available online: https://survivorsfund.org.uk/news/solar-cooking/ [Accessed 22 September 2019].

Thacker, S., Adshead, D., Fay, M., Hallegatte, S., Harvey, M., Meller, H., O’Regan, N., Rozenberg, J., Watkins, G., Hall, J.W. (2019). Infrastructure for sustainable development. Nature Sustainability, 2 (324). https://doi.org/10.1038/s41893-0190256-8.

Santika W. G., Anisuzzaman, M., Bahri, P.A., Shafiullah, G.M., Rupf, G.V., and Urmee, T. (2019). From Goals to Joules: A Quantitative Approach of Interlinkages between Energy and the Sustainable Development Goals. Energy Research \& Social Science, 50(2019), pp. 201-14. https://doi.org/10.1016/j.erss.2018.11.016. 
Waage, J., Yap, C., Bell, S., Levy, C., Mace, G., Pegram, T. et al. (2015). Governing the UN Sustainable Development Goals: interactions, infrastructures, and institutions. The Lancet Global Health, 3(5), pp. 251-252.

Weitz, N., Carlsen, H., Nilsson, M., and Skånberg, K. (2018). Towards systemic and contextual priority setting for implementing the 2030 Agenda. Sustainability Science, 13, pp. 531-548. https://doi.org/10.1007/s11625-017-0470-0.

World Bank (2014). Clean and improved cooking in sub-Saharan Africa. Available at: http://documents.worldbank.org/curated/en/164241468178757464/pdf/98664REVISED-WP-P146621-PUBLIC-Box393185B.pdf [Accessed: 15 August 2019].

World Bank (2017). Project Information Document/Integrated Safeguards Data Sheet (PID/ISDS). Rwanda Renewable Energy Fund (P160699). Available at: http://documents.worldbank.org/curated/en/599771487529927175/pdf/ITM00184P160699-02-19-2017-1487529923719.pdf [Accessed: 27 July 2019].

World Health Organization (WHO) and World Bank (2015). Access to Modern Energy Services for Health Facilities in Resource-Constrained Settings. Available at: https://apps.who.int/iris/bitstream/handle/10665/156847/9789241507646_eng.pdf;jse ssionid=6E8C05EB406B4354E52FB633925B0939? sequence=1 [Accessed: 27 July 2019].

World Health Organization (WHO) (2016). Burning Opportunity: Clean Household Energy for Health, Sustainable Development, and Wellbeing of Women and Children. Available at: https://apps.who.int/iris/bitstream/handle/10665/204717/9789241565233 eng.pdf?se quence $=1$ [Accessed: 27 July 2019]. 
[1] Ensure universal access to affordable, reliable and modern energy services (7.1); increase the share of renewable energy in the global energy mix (7.2); double the global rate of improvement in energy efficiency (7.3); enhance international cooperation to facilitate access to clean energy research and technology (7.a); and promote investment in energy infrastructure and clean energy technology (7.b).

[2] Only academic journal articles and documents accessible to the public have been included in this analysis.

[3] Umuganda is a practice rooted in Rwandan culture and refers to community works held on every last Saturday of the month. Girinka is a social programme known as 'One Cow per Poor Family' whereby "a farmer is given an in-calf heifer and is obliged to pass on to the first female offspring to another program beneficiary who is selected by local administration authorities" (RAB, n/d).

[4] Under this domain, SDG2 has the most potential trade-offs: 4 out of a total of 7. 